\title{
BIBLIOGRAFÍA COMENTADA «DE"Y «SOBRE» ADELARDO LÓPEZ DE AYALA (1829-1879)
}

MARÍA MARTÍNEZ-CACHERO ROJO

\begin{abstract}
Adelardo López de Ayala no es un escritor muy atendido bibliográficamente, así en cuanto a ediciones de sus obras como en la llamada bibliografía secundaria y el repaso de las 78 entradas bibliográficas ofrecidas seguidamente lo confirma. Las divido en bibliografía «de» y bibliografía «sobre»; en el primer apartado sigo un orden cronológico según la fecha de su publicación y en el segundo ordeno las entradas alfabéticamente.

De una parte, tenemos dos ediciones de Obras Completas - que no lo son exactamente-, aparecidas en 1881-1885 (1) y 1965 (2), iguales entre sí salvo el extenso prólogo del catedrático universitario José María Castro y Calvo (26) que lleva la segunda. Añádanse en este apartado las contribuciones debidas a Antonio Pérez Calamarte, seudónimo utilizado por Adolfo Bonilla y San Martín, quien dio a conocer los dieciséis capítulos de Gustavo, novela inacabada (4), la versión original de la epístola ayalina a Emilio Arrieta (5) y las cartas cruzadas entre López de Ayala y Teodora Lamadrid (7), escritos conservados entre los papeles de Arrieta, tío de Bonilla y San Martín. Me ha sido posible sumar a ese conjunto dos poemas de distinto asunto y época $(10,11)$.

En el apartado «sobre» cabe destacar tres libros dedicados íntegramente a nuestro autor, obra de Conrado Solsona y Baselga (71) - se ocupa preferentemente de su actividad política-, Luis de Oteyza (60) —-donde la política y la literatura ayalinas resultan hostilmente tratadas- y Edward W. Coughlin (34) - que atiende tanto a la biografía como a la obra de López de Ayala-. Forman otro grupo dentro de este apartado los testimonios de algunos colegas que le conocieron y trataron - caso de Eusebio Blasco (20), Emilio Gutiérrez Gamero (50) o Julio Nombela (59) -, testimonios más bien anecdóticos. Las reseñas periodísticas de los estrenos teatrales de Ayala son numerosas, pero la impresión obtenida tras la lectura que he hecho de bastantes de ellas es que resultan, salvo contadas excepciones - caso de Clarín (29) y de Revilla (65): ambos comentan Consuelo-, meras gacetillas que sólo dan cuenta del argumento de la pieza y
\end{abstract}


del trabajo de los intérpretes. Dos académicos de la Lengua y cordiales amigos de su compañero, el Marqués de Molins y Jacinto Octavio Picón, se ocuparon elogiosamente de Ayala en distintas circunstancias: con motivo de su ingreso como académico de número, el primero (58), y como prologuista, el segundo, de Consuelo, incluida en la antología Autores dramáticos contemporáneos y joyas del teatro español del siglo XIX (Madrid, 1882, pp. 377-399 del tomo II), trabajo aparecido también en La España Moderna (64). Finalmente, pudiera formarse otro grupo con aquellos libros publicados en el siglo XIX o en el XX, obras colectivas o no, en cuyas páginas aparece estudiado con alguna amplitud nuestro autor, así por ejemplo en: Narciso Alonso Cortés (12), César Barja (17), Francisco Blanco García (18), Gonzalo Calvo Asensio (22), David T. Gies (46) o Francisco Ruiz Ramón (69).

\section{BIBLIOGRAFÍA «DE»}

1. Un hombre de estado (Drama en cuatro actos y en verso), Madrid, 1851. $1^{\text {a }}$ edición.

2. Los dos Guzmanes (Comedia en tres actos y en verso), Madrid, 1851.

3. La estrella de Madrid (Zarzuela en tres actos y en verso), Madrid, 1853.

4. El curioso impertinente (novela de Cervantes reducida a drama en cuatro actos y en verso), Madrid, 1853.

5. Rioja (drama en cuatro actos y en verso), Madrid, 1854.

6. Guerra a muerte (Zarzuela en un acto y en verso), Madrid, 1855.

7. Los comuneros (Zarzuela en tres actos y en verso), Madrid, 1855.

8. Haydée o el secreto (Zarzuela en tres actos y en prosa), Madrid, 1855.

9. «Cantata para la solemne coronación de Don Manuel José Quintana. Letra de D. Adelardo López de Ayala, música de D. Emilio Arrieta», en Corona poética dedicada al Exmo. Sr. D. Manuel José Quintana, con motivo de su coronación, por los redactores de La ESPAÑA MUSICAL Y LITERARIA y publicada por D. José Marco, director de la sección literaria del referido periódico, Madrid, 1855; la Cantata va en páginas 76-78./ / También figura («Cantata para el acto de la Coronación») en las pp. 8384 de Coronación del eminente poeta D. Manuel José Quintana, celebrada en Madrid, a 25 de marzo de 1855, Madrid, 1855.

Su texto es el siguiente:

\section{CORO GENERAL}

Nobles vates inspirados por el genio de la gloria, celebrando la victoria, 
vuestro canto levantad.

Que la patria al fin os dice

con enérgica elocuencia:

«Alcanzó la inteligencia galardón y libertad».

\title{
ESTROFA PRIMERA
}

De gozo en este día el alma se dilata, que al fin la patria mía dejó de ser ingrata. Cuando su gloria cantes en la eternal mansión, mitiga de Cervantes la justa indignación.

\section{CORO GENERAL}

Idem.

\section{ESTROFA SEGUNDA (MUJERES)}

\author{
Lloraste la amargura \\ de la que nace hermosa, \\ corone la hermosura \\ la frente luminosa. \\ Jamás del genio ardiente \\ muriera el resplandor, \\ si el genio solamente \\ rindiera nuestro amor.
}

\section{CORO GENERAL}

Idem.

'0. El conde de Castralla (Zarzuela en tres actos y en verso), Ma1855 .

Igualmente no se ofrece en las Obras Completas el texto de un » inserto en el artículo Poesía pura, publicado en el número LII dre Cobos (20-V-1856); la anonimia de los originales aparecidos ste «periódico de política, literatura y artes» dificulta al máximo la identificación de sus autores, miembros de un cuerpo de redacción cuyos nombres sólo eran conocidos entre periodistas y políticos. En el caso de Adelardo López de Ayala, integrante del mismo, existe la casi certeza de que a él se debe el mencionado artículo, donde figuran los versos de un himno cuyo contenido fue denunciado por el Promotor Fiscal Sr. Massa y Sanguinetti al estimar «las coplas como subversivas en primer grado, porque desacreditan a las Cortes»; celebrado el correspondiente juicio (19 de 
junio de 1856), por diez votos contra dos fue absuelto el periódico, defendido en tal ocasión por López de Ayala, cuya actuación agradece El Padre Cobos con las siguientes palabras: «Todos reconocían en su defensor a uno de nuestros primeros escritores dramáticos: ayer el orador se levantó de un golpe a la altura del poeta. El Padre Cobos tendrá siempre la satisfacción y el orgullo de haber recogido las primicias de un talento que tan envidiables frutos ha de alcanzar en la tribuna».

En esa intervención (que puede leerse en el «Suplemento» al número LX, 30-VI-1856), su autor repasa verso a verso dicho himno con el objeto de rebatir las alegaciones del fiscal, desmesuradas e injustas puesto que el asunto de versos tan inocentes (según su defensor) no es otro que hacerse eco, con humor, de la resistencia mostrada por los señores diputados a la disolución de las Cortes que por esas fechas proyectaba un gobierno presidido por Espartero. Ayala ironiza en un pasaje de su extenso discurso acerca de la calidad de las coplas impugnadas pues «si el caballero Fiscal las denunciara como atentatorias a la buena literatura, yo me pusiera de su parte a sostener su acusación», y añade que «si estos versos son tan malos como he dicho es porque el Padre adrede los ha hecho así para excitar la risa».

Estos son los versos:

\section{H I M N O}

CORO

¿Que nos van à quitar el oficio! iSostened, chascanautas, la lid! ¿Córtes haya hasta el día del juicio!

¡Córtes, Córtes que no tengan fin!

\section{GRUPO PRIMERO}

Después ¡ay! de haber reconocido que es muy bueno ser Constituyente, (porque superabundantemente es mejor que ser Constitución), estando ya cerca del verano, à veinte de este mes, cuando más, vuelve a Madrid el Duque y ...jichascás! noa amaga la disolución.

\section{CORO}

¿Que nos van à quitar el oficio! etc

\section{FRACCIÓN SEGUNDA}

A fuerza de agua y azucarillos embelesábamos al concurso, 


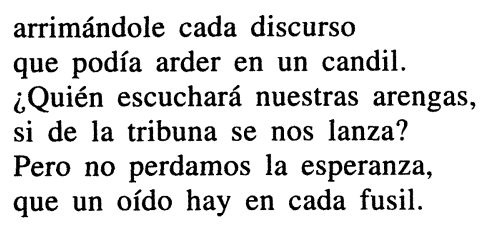

\section{PELOTÓN TERCERO}

Si vence el proyecto de clausura, acabó la higuera de dar higos; ni los parientes ni los amigos del presupuesto disfrutarán. ¡Sus! ¡Sus! ¡A las lenguas! ¡A las lenguas! ¡Guay! que tal vez, si somos echados, al país los nuevos Diputados desconstitucionalizarán!

\section{CORO}

¿Que nos van à quitar el oficio! etc.

La antes dicha «casi certeza» tiene como fundamento el hecho de que por estos días apareció en el diario Las Novedades un artículo cuyo asunto era el mismo del «Himno» y cuya autoría reconoce López de Ayala en su defensa ante el Fiscal: «Como a mí la injusticia me es insoportable, iritado de la saña con que se persigue a este periódico [El Padre Cobos], quise buscar un medio para que los mismos Fiscales de imprenta se viesen obligados a confesar su odiosa parcialidad. Las mismas ideas de las coplas denunciadas las hice circular por una parte de la prensa [subrayo]».

12. El tejado de vidrio (Comedia en cuatro actos y en verso), Madrid, 1856. Hay también ediciones de los años 1857, 1863, 1877 y 1902.

13. El agente de matrimonios (Zarzuela en tres actos y en verso), Madrid, 1862.

14. El nuevo don Juan (Comedia en verso), Madrid, 1863.

15. El alcalde de Zalamea (Comedia en tres actos y en verso de Don Pedro Calderón de la Barca, refundida por Don Adelardo López de Ayala), Madrid, 1864.

16. El tanto por ciento (Comedia en tres actos y en verso), Madrid, 1864. Hay también ediciones de los años 1878, 1892 y 1943.

17. El conjuro (Entremés de don Pedro Calderón de la Barca manoseado por Adelardo López de Ayala y puesto en música por Emilio Arrieta), Madrid, 1866. 
18. Memoria presentada a las Cortes Constituyentes por el Ministro de Ultramar Don Adelardo López de Ayala el 22 de febrero de 1869, Madrid, 1869.

19. Discursos leídos ante la Academia Española en la recepción de don Adelardo López de Ayala. (Contestación del Sr. Marqués de Molins), Madrid, 1870.

20. Consuelo (Comedia en tres actos y en verso), Madrid, 1878. Hay también ediciones de los años 1882, 1904, 1911 (New York, Holt and Co. edición de A.M. Espinosa), 1920, 1943 y 1966 (Madrid, Aguilar, edición de Antonio Espina).

21. Los dos artistas, Madrid, 1882.

22. De tal siembra, tal cosecha, Barcelona, 1899.

23. Obras, Madrid, A. Pérez Dubrull (Colección de Escritores Castellanos), 1881-1885; (Tomo I: Presentación de don Manuel Tamayo y Baus, Un hombre de estado; Los dos Guzmanes; Guerra a muerte. Tomo II: El tejado de vidrio; El conde de Castralla, Tomo III: Consuelo; Los comuneros. Tomo IV: Rioja, La estrella de Madrid; La mejor corona... Tomo V: El tanto por ciento; El agente de matrimonios. Tomo VI Castigo y perdón; El nuevo don Juan. Tomo VII: poesías y proyectos de Comedias.

24. La refundición ayalina de El alcalde de Zalamea -El alcalde de Zalamea, comedia en tres actos y en verso de D. Pedro Calderón de la Barca, refundida por D. Adelardo López de Ayala, Madrid, 1881; 86 pp.-.

25. Gustavo, novela inédita. Publícala Antonio Pérez Calamarte, Revue Hispanique, XIX, 1908, pp. 8-133.

Precede al texto una breve introducción informativa (pp. 5-7), firmada por Pérez Calamarte, quien advierte: «Respetamos escrupulosamente la ortografía del original, aunque variamos la puntuación y la acentuación en algunos lugares».

26. Epístola de Adelardo López de Ayala, Revue Hispanique, XII, 1905, pp. 5-9.

Es la dirigida a Emilio Arrieta y la edita ahora Adolfo Bonilla y San Martín. «Los lazos de parentesco que con el gran maestro Arrieta nos ligaron hicieron caer en nuestras manos el original de la susodicha Epístola y una copia sin terminar, pero también autógrafa, [...]. Con arreglo al primero, y anotando las variantes de la segunda, restablecemos el texto de la Epístola, respetando escrupulosamente la ortografía del autor».

27. Epistolario inédito de Ayala, Revue Hispanique, XXVII, 1912, pp. 499-622.

Son 110 cartas de Ayala a Teodora Lamadrid, actriz famosa que representó algunas obras suyas, entre quienes hubo una apasionada relación amorosa; a manera de apéndice se incorporan 18 cartas de la actriz a Ayala.

El conjunto lo dio a conocer Antonio Pérez Calamarte, que advierte: «damos a luz una colección de cartas íntimas que llegó a nuestras manos 
[...] y que contiene interesantes datos para la biografía del poeta y para la historia literaria y artística de su tiempo. Por consideraciones que fácilmente se sobreentienden hemos omitido el nombre de la dama, sustituyéndole por una inicial [T], seguida de puntos suspensivos. El período que las cartas comprenden abarca, aproximadamente, desde el año 1852 hasta el 1867». Calamarte anota algunas alusiones y referencias.

28. Adelardo López de Ayala. Sus mejores versos, prólogo de Tomás Borrás, Madrid, 1928, $\mathrm{n}^{\circ} 8$ de la colección «Los Poetas».

29. Cartas de algunos literatos a D. Emilio Arrieta [...], edición de M. Serrano y Sanz, Boletín de la Real Academia Española, XIX, 1932, pp. $118-134$ y $362-387$.

Las de Ayala ocupan las páginas 373-376, son seis y fueron escritas en Guadalcanal o en Madrid, sin precisar año.

30. Obras completas, Madrid, Atlas, (Colección «Biblioteca de autores españoles»), 1965. Edición y estudio preliminar de José María Castro y Calvo, que sigue fielmente la división de las anteriores obras completas.

31. La alta comedia: Antología teatral de Tamayo y Baus y López de Ayala, Madrid, Conculsa, (Colección «Primera Biblioteca de Literatura Española»), 1970.

\section{BIBLIOGRAFÍA «SOBRE»}

32. Alas, Leopoldo. Vid. Clarín.

33. AlONSO CORTÉS, Narciso: «El teatro español en el siglo XIX», en Historia General de las Literaturas Hispánicas, t. IV segunda parte, pp. 293-295, Barcelona, editorial Barna, 1957.

Los celos sirven como tema para sendas comedias de Tamayo y Baus y Ayala, La bola de nieve y El tejado de vidrio, respectivamente, «muy superior» ésta a su ocasional compañera y ejemplo de la faceta más interesante del teatro ayalino, pues junto a ella «nada significan» las obras pertenecientes a la faceta histórica. A.C. concluye con el siguiente subido elogio: «En López de Ayala se aúnan las cualidades inherentes al comediógrafo perfecto. Antes que nada, el espíritu selecto de poeta, que traduce sus pensamientos en nítidos versos; después, el dominio omnímodo de la escena y de todos sus resortes. Planeaba sus obras Ayala detenida y concienzudamente y así se explica que sean un modelo de orden y de claridad y que todas sus situaciones e incidencias estén preparadas y resueltas del modo más oportuno».

34. Alltadill Y TEIXIDó, Antonio: El tanto por ciento. Novela escrita sobre el argumento de la comedia de Adelardo López de Ayala, Barcelona, 1863, $555 \mathrm{pp}$. en $4^{\circ}$ y láminas de planas litografiadas a dos tintas. 
A.T. (1828-1880) fue redactor o colaborador de varios periódicos madrileños y barceloneses, además de prolífico novelista, especializado en asuntos bíblicos.

No me ha sido posible acceder a este libro, anunciado hace años en un catálogo de una librería de viejo madrileña.

35. ARTigas, Miguel: «A propósito de un libro», Boletín de la Biblioteca Menéndez Pelayo, 1919, n. ${ }^{\circ} 24$, pp. 48-52.

Reciente la publicación de Los hombres de toga en el proceso de don Rodrigo Calderón, libro debido a Ángel Ossorio y Gallardo, ofrece A. el texto de una carta inédita de Ayala a Manuel Cañete, muy conocido crítico literario y muy amigo suyo, informándole acerca de los despropósitos y equivocaciones de algunos comentaristas (Eugenio de Ochoa o los anónimos de El Clamor y La Nación) del estreno de Un hombre de estado y, también, de su propósito al escribir esta obra; Ayala pide a Cañete que hable de ella pues «su silencio está haciendo más daño que todos estos con lo que han dicho».

36. Asensio Centeno, M.: «Revista teatral: Consuelo, El nudo gordiano», La Semana Literaria (Revista de Literatura, Ciencias y Artes), La Coruña, 1879, n. ${ }^{\circ} 26$.

Repaso bastante literal (o escasamente interpretativo) de la pieza ayalina, admirable por varios motivos: «la fluidez de su versificación, la hilación y oportunidad de las escenas, el interés constante que despierta, la verosimilitud y moralidad de su argumento y lo grandioso del desenlace, unido a un estilo ameno, dulce y armonioso [...]».

37. AZORÍn: «Un retrato de mujer», $A B C$, Madrid, 13-IV-1946.

Señala Azorín algunas semejanzas entre la protagonista de Consuelo (1878), drama de Ayala, y Hedda Gabler, la heroína de Ibsen en la obra así titulada (1891).

38. BARJA, César: Libros y autores modernos. Siglos XVIII y XIX, Madrid, 1933, pp. 220-234.

En el capítulo XVII («El drama de transición») Barja se refiere a Ayala y a Tamayo y Baus como representantes del «imperio del buen sentido» después del ataque de epilepsia sentimental y de exaltación imaginativa que supuso el romanticismo; cultivadores ambos de un teatro con «finalidad moral y docente» relativa a la sociedad coetánea. Pero aunque ésta sea la dirección más conocida y celebrada de la dramaturgia ayalina, que guarda «cierta semejanza con el teatro de Ruiz de Alarcón», Barja advierte que también sus piezas de asunto histórico contienen alguna enseñanza: en $U n$ hombre de estado es «la apología de la vida retirada y modesta» y en Rioja, la apología de «la caballerosidad, la nobleza y la abnegación».

39. BlANCO GARCÍA, Francisco: La literatura española en el siglo XIX, parte segunda, tercera edición, Madrid, 1910, pp. 179-195.

El crítico agustino muestra una considerable complacencia por la obra 
de Ayala, escritor de «gusto acendrado» que acertó a combinar «lo más templado y aceptable de las audacias románticas con el acicalamiento y la corrección del clasicismo» tanto en sus poemas, cuya «joya exquisita y por excelencia» es la epístola a Emilio Arrieta, como en las piezas teatrales, sobre todo en aquellas de marcada intención aleccionadora (El tejado de vidrio y Consuelo, en primer lugar), emparejable por ello con Ruiz de Alarcón; le convence menos Un hombre de estado ya que existe demasiada rapidez, atropellamiento incluso en el desenvolvimiento de la fábula y el lenguaje ofrece «las exuberancias y frondosidades de un lirismo inoportuno $[\ldots] \gg$.

40. BlASCO, Eusebio: «Epístola a D. Adelardo López de Ayala, ausente de la Corte», en Malas costumbres. Apuntes de mi tiempo, seguidos de algunos bocetos biográficos y poesías, Madrid, 1880, pp. 303-309.

Epístola en tercetos que el autor dirige a su amigo Ayala retirado a la sazón en Guadalcanal, su patria chica, exhortándole a que, lejos del tráfago madrileño, goce «en calma la plácida ventura/ que en su seno te da suelo nativo,/ rica, feraz, frondosa Extremadura».

41. - : «yala», en Los de mi tiempo. Semblanzas varias (segunda serie), Madrid, segunda edición, s. a., pp. 105-117.

Blasco fue amigo de Ayala y su semblanza está llena de simpatía hacia el personaje, de quien se ofrece primero una breve biografía - estudiante de Leyes en Sevilla, periodista en El Padre Cobos, por ejemplopara recordar después el éxito obtenido por El tanto por ciento - «un verdadero acontecimiento. Madrid entero acudió a verla»- $\mathrm{y}$, también, la amistad fraternal entre Ayala y Emilio Arrieta - «el mismo techo los cubría, la misma chimenea los calentaba»-y las animadas tertulias (de ocho de la tarde a once de la noche) en su casa de la calle de San Quintín, de las que $B$. era asiduo.

42. BORRÁs, Tomás: Adelardo López de Ayala. Sus mejores versos, prólogo de Tomás Borrás, Madrid, 1928, pp. 5-8, n. ${ }^{\circ} 8$ de la colección «Los Poetas».

Breve pero elogiosamente prologa $\mathrm{B}$. este volumen de 80 páginas que contiene casi todas las composiciones poéticas de Ayala, un poeta (a su juicio) más bien parnasiano puesto que «no busca música, busca escultura» y se complace en la imitación de algunos autores del Siglo de Oro y «así tiene estrofas rivales de las de Herrera y Rioja y sonetos tan desesperadamente perfectos como los de Argensola y Arguijo.

43. Calvo Asensio, Gonzalo: El teatro hispano-lusitano en el siglo XIX. Apuntes críticos, Madrid, 1875, pp. 161-174.

Aún no se había estrenado Consuelo y por eso el apunte relativo al teatro ayalino queda incompleto. Atiende a las piezas de asunto histórico (Un hombre de estado o Rioja), no plenamente logradas, y dedica grandes elogios a las posteriores: El tejado de vidrio, «la más acabada y caracte- 
rística», superior a El hombre de mundo, de Ventura de la Vega; El tanto por ciento, muestra de «una ingeniosa fábula, fácil y habilísimamente conducida» y cuyos personajes poseen «caracteres bien contrastados»; y $E l$ nuevo Don Juan, que es «comedia bellísima, la intención sana [y] magistral su desarrollo». En todas ellas se echa de ver que su autor es «un pensador profundísimo» y observador notable de la sociedad coetánea.

44. CAÑAMAQUE, Francisco: Los oradores de 1869. Aparisi y Guijarro, Ayala, Cánovas, Castelar, Echegaray, Figueras, Manterola, Martos, Moret, Olózaga, Pi y Margall, Posada, Prim,..., Madrid, 1879.

Semblanzas de primera mano de los más destacados prohombres de la situación política tras la revolución septembrina en su faceta de oradores parlamentarios; en las páginas 6-7 figuran la descripción física de Ayala — «Frente ancha, tersa, espaciosa; ojos negros, serenos, grandes; bigote poblado, enorme, retorcido; pera larga, espesa, cuidada; melena artística, aceitosa, poética; rostro ovalado, lleno, severo; cabeza imponente, bella, escultural»- y la siguiente caracterización de su oratoria: es «un gran orador, si bien algo dramático, acaso por sus relaciones teatrales, por su amor a las tablas; su voz es [...] un poquillo oscura; su enunciación, tarda y premiosa; su aspecto en la tribuna, grave y digno; su palabra, pura, galana y correcta».

45. CARABIAS, Josefina: 1878, Madrid, Revista de Occidente, 1945, pp. 97-102.

Son unas páginas donde la periodista J.C. refiere, basándose en la prensa de aquellos días, las vicisitudes del estreno de Consuelo (30-III-1878), desde el intento de disuadir a Ayala de que afrontase en su condición de presidente del Congreso de los diputados semejante riesgo - «no podía exponerse a una posible rechifla del público»- hasta el rotundo éxito obtenido al que contribuyó la excelente interpretación de actrices y actores (Antonio Vico, entre ellos). El autor salió a saludar a los entusiasmados espectadores y hubo quienes vieron la obra varias veces (como José Francos Rodríguez): "Yo me hinché las manos de tanto palmotear y llegué a saberme de memoria la comedia de Ayala a fuerza de asistir a las representaciones».

46. CASALDUERo, Joaquín.: Historia de la Literatura Española. Volumen III: Siglos XIX y XX, Madrid, Guadiana, 1974, pp. 152-154.

Dentro de un amplio capítulo dedicado a nuestro teatro decimonónico, C. se ocupa solamente de Consuelo, superior a Lo positivo, de Tamayo y Baus, y montada la acción en unos cuantos motivos o elementos de la época: económicos, morales y culturales pero C. piensa que Ayala «no ha trasmitido al espectador o al lector el nuevo tipo de héroe creado por las altas finanzas [...]. Tampoco Consuelo es un carácter dramático. $\mathrm{Ni}$ se ha profundizado en su realidad, ni se ha querido hacer de ella una rebelde $[\ldots] »$. 
47. Castro y Calvo, José María: Obras completas de Don Adelardo López de Ayala, edición y estudio preliminar de ..., Madrid, Biblioteca de Autores Españoles, CLXXX, 1965, pp. VII-CXXXVII.

El catedrático de la Universidad Central de Barcelona, que tanta atención dedicó a nuestra literatura decimonónica, encabeza su edición con un extenso prólogo («Ayala y su época») en el que utiliza cumplidamente la bibliografía «sobre» existente y añade sugerencias y estimaciones propias; su valoración última es que Ayala «no merece ser olvidado. Su aportación al teatro español del siglo XIX, aún con todos sus defectos, es interesante y digna del mejor recuerdo por lo que representa y como enlace y transición del drama romántico al moderno. El orador, el poeta, el escritor en prosa, en fin, cuanto aparece en Ayala, está vinculado a su tiempo [...]».

48. Castro y Serrano, José de: Artículos en El Contemporáneo, Madrid, días $18,19,21,23$ y 25 de junio de 1861 .

Para C. y S. carecen de fundamento los reparos formulados por Vicente Rodríguez Varo (número 67) contra la pieza ayalina El tanto por ciento, que es «una obra moral en la cual el dramaturgo solamente trataba de corregir los vicios de la sociedad».

49. CEJADOR Y FRAUCA, Julio: Historia de la Lengua y Literatura Castellanas..., tomo VIII (Períodos de la época realista), pp. 66-71; cito por la edición facsímil, Madrid, Gredos, 1972.

C. y F. sitúa a Ayala en 1851, año del estreno de Un hombre de estado, e informa de que las «36 primeras representaciones de El tanto por ciento le valieron 42.200 reales, una corona de oro por suscripción que abrió [el periódico] La Iberia [y] un precioso Álbum [de los literatos compañeros]». Afirma rotundamente que «no valía Ayala para asuntos históricos» y resalta la importancia de sus obras de aleccionamiento moral que son «invectiva contra el positivismo de la vida moderna y la falta de levantados pensamientos y de nobles miras en los hombres de hoy». Se pierde un tanto en relaciones y cotejos con Tamayo y Baus y Moratín hijo; lamenta «tanto politiquear [de Ayala] perdiendo el tiempo para el arte»y reconoce el mérito de sus poemas líricos.

50. «ClARÍN»: «Consuelo», en Solos de Clarín, Madrid, 1881, pp. 81-91.

Juicio muy elogioso de Consuelo, drama y no comedia según el crítico, que lo considera nueva insistencia de su autor en la denuncia de «el verdadero mal del siglo» - la supervaloración del dinero- que aquí «ha penetrado en la fuente de toda ventura, en el santuario del amor, ha profanado lo ideal y ha corrompido a la que debiera ser vestal [...] del amor puro», comportamiento el de la protagonista que no puede quedar impune como se ve en el final de la obra, que «encierra una lección profunda». El personaje Fulgencio resulta con sus hechos y dichos símbolo del hombre «vulgar», carente de «cualquier arranque de nobleza y virtud». 
51. - Cánovas y su tiempo (primera parte), Folletos literarios II, Madrid, 1887, pp. 91-92.

Comenta «Clarín» el prólogo que puso Cánovas a las obras de José Moreno Nieto y no está de acuerdo con su afirmación de que Ayala era un gran orador; sostiene en cambio que «era un buen poeta; escribió una comedia, Consuelo, que es acaso la mejor entre las modernas españolas; escribió otras muy dignas de elogio, como El tanto por ciento, y dejó además excelentes poesías líricas, algunas dignas de ser modelo por la hermosura y transparencia de la forma; pero Ayala no fue orador ni tuvo pretensiones de tal».

52. ClARKE, Dorothy C.: «Hiatus, synalepha and line length in López de Ayala's octosyllables», Romance Philology, I, 1947-48, pp. 347-356.

Examen y ejemplificación de la medida de los octosílabos ayalinos de Consuelo, alterada si se da alguno de los casos siguientes: a) cuando las vocales son del mismo timbre; b) cuando una de las vocales forma parte de una palabra inacentuada monosílaba o bisílaba, c) cuando la primera vocal es la $o$ de la primera persona de un presente de indicativo.

53. CorTizo, M. ${ }^{a}$ Encina: Emilio Arrieta. De la ópera a la zarzuela, Instituto Complutense de Ciencias Musicales (colección Música Hispana 9), Madrid, 1998.

En este muy documentado libro biográfico-crítico sobre la vida y la obra del compositor Emilio Arrieta aparece frecuentemente el nombre de Adelardo López de Ayala, su entrañable amigo con quien compartió casa en Madrid (calle de San Quintín, número 8), ambos solteros, durante bastantes años. De esa relación personal, de su participación en empresas colectivas como el periódico satírico-político El Padre Cobos (1854-1856), de su colaboración zarzuelística (libretos de Ayala y música de Arrieta) o de pormenores de la biografía del primero (como el nombramiento de director del Real Conservatorio de música y declamación, 1865) informa cumplidamente $\mathrm{C}$., que más de una vez utiliza noticias de la prensa de la época.

54. Cossío, José María de: Cincuenta años de poesía española (18501900), Madrid, 1960, tomo I, pp. 693-698.

Dichas páginas corresponden al capítulo XVI, «Poetas clasicistas», donde Ayala figura junto, v.g., a Menéndez Pelayo, autor de una obra poética «exigua [en cantidad] pero de un nivel elevado» en la que destacan los sonetos - los amorosos, especialmente- y dos epístolas a otros tantos amigos; versos los ayalinos que (según C.) por «la expresión, las metáforas, los mismos temas, corresponden a otro ambiente poético [distinto] del que entonces se respiraba en España y pesaba en la orientación de sus poetas». 1977 
C. ha compuesto un libro sobre López de Ayala ajustándose a las normas directoras de las «Twayne's World Authors Series» en cuyos volúmenes - un autor en un libro- se ofrecen: una cronología-biografía del escritor de que se trate, un examen de su producción y una bibliografía selecta (fuentes primarias y secundarias). En el examen de la obra ayalina, C. dedica atención a sus composiciones poéticas - algunas, como los sonetos «A un pie» o «Al oído», le recuerdan por su levedad rococó a Meléndez Valdés-; la faceta del teatro de Ayala correspondiente a la alta comedia le parece que resulta en general poco realista y respecto, v.g., de El tejado de vidrio lo estima como una reacción o discrepancia con la apología del personaje de Don Juan realizada por el romanticismo e, igualmente, como denuncia de la postergación sufrida por la mujer pues (según Julia): «Todas lloramos,/Dolores: todas pagamos/los delitos de los hombres./Con muestro llanto/florece su placer».

56. DíAZ DE ESCOVAR, Narciso y Francisco de P. LASSO DE LA VEGA: Historia del teatro español. Comediantes, escritores, curiosidades escénicas, Barcelona, Montaner y Simón, 1924, tomo I, pp. 426-429.

Dos errores cronológicos: el año de nacimiento de Ayala - que no fue 1831 - y el del estreno de Consuelo — que no fue 1877- y una cierta insistencia en dar cuenta de su actividad política. Sus primeras obras dramáticas - las de asunto histórico- «se resienten de cierta inexperiencia, de cierta obscuridad, de cierta confusión en el fondo y de falta de recursos, de variedad y de debilidad plástica»; otra cosa son El tejado de vidrio, «inmejorable comedia», y El tanto por ciento, «lindísima comedia». De Consuelo sólo se dice que es obra «admirablemente planeada y escrita».

57. DÍAZ Y PÉREZ, Nicolás: Diccionario histórico-biográfico, crítico y bibliográfico de autores, artistas y extremeños ilustres, Madrid, 1884, tomo I, pp. 497-508.

En las doce páginas de la semblanza de Ayala, D. y P. repara especialmente en sus versos y afirma que «en los sonetos [ofrece el texto de siete de ellos como ejemplo probatorio] está muy por cima de nuestro gran ingenio Quevedo, y sólo puede aventajarle el inmortal Petrarca»; elogia su oratoria con gran entusiasmo - «su estilo dramático, aquella frase pura y castiza, aquellas palabras que eran un prodigio de belleza, de corrección y galanura; sus períodos rotundos y armoniosos; sus apóstrofes elocuentísimos y llenos de vigor, le conquistaron la admiración y el respeto de adversarios y parciales»- y añade que «no tenía condiciones de hombre de gobierno». Pero desde la página 502 hasta el final, la enfermedad, la muerte y el entiero del biografiado se convierten en protagonistas exclusivos y así sabemos del progreso de la enfermedad hora a hora, el nombre de los médicos que le asistieron o el de los amigos que le visitaron, etc., etc. Finalmente, D. y P. informa de su amistad con el escritor. 
58. DíEZ TABOADA, Juan María:«Los curiosos impertinentes en el teatro», Revista de Literatura, 114, 1995, pp. 463-464.

La novela de El Curioso impertinente que figura en el Quijote de 1605 fue objeto de varias adaptaciones teatrales entre las que cuenta la debida a Adelardo López de Ayala y Antonio Hurtado, estrenada en 1853 y en la cual se advierte como rasgo peculiar «la fuerte contención de las efusiones sentimentales que evita la propensión al melodrama tan propia de la época, y que mantiene la obra en los márgenes contenidos de la tragedia y dentro, también, de los márgenes que marca la tradición cervantina».

59. - : Historia de la Literatura Española. Siglo XIX (I), coordinador Guillermo Carnero, Madrid, Espasa Calpe, 1997, pp. 403-408.

Van juntos en estas páginas Ayala y Tamayo y Baus en cuanto fueron los más destacados cultivadores en nuestro teatro decimonónico de la modalidad llamada alta comedia; «correcto, lírico, moralizante y a la vez calderoniano», el primero, autor, v. g., de El tejado de vidrio, cuya característica de crítica social está aún envuelta en un ambiente determinadamente sentimental», y de Consuelo que, pese a sus méritos — bien definidos los personajes, por ejemplo-, se queda «sin traspasar los límites que le impone el moralismo típico de los años centrales del siglo XIX [...]». 212.

60. EchegaraY, José: Recuerdos, Madrid, 1917, tomo III, pp. 208-

Entre los casos de oportunidad o no-oportunidad de los discursos parlamentarios que E. recuerda haber conocido directamente está el pronunciado por Ayala, ministro entonces de Ultramar en un gobierno presidido por el duque de la Torre, y que trajo como consecuencia la inmediata dimisión del orador; E., que refiere extensamente el suceso, concluye con estas palabras: «De manera que un discurso admirablemente artístico, y con cuyo fondo estaban conformes todos los de la Unión Liberal, le costó la vida ministerial a un ministro simpático y prestigioso. ¿Por qué? Sólo por falta de oportunidad».

61. ESPADAS Burgos, Manuel: «El misterio de El Padre Cobos», Revista de Literatura, 13-14, 1955, pp. 208-212.

E. B. hace algunas precisiones acerca de la presumible autoría de secciones y textos en este periódico de oposición al gobieno progresista de Espartero, cuyos redactores - Ayala, entre ellos- deseaban mantener para su trabajo el más completo anonimato.

62. EsPINA Y CAPO, Antonio: Notas del viaje de mi vida, Madrid, 1926, tomo II, pp. 294.

«Ayala escribió poco, pero su teatro quedará para siempre en la dramática española; fue llamado por Hartzenbusch el Calderón de la época moderna. En el estreno de El tanto por ciento sus personajes eran de tal calaña, que la reina Isabel II le preguntó si había escogido sus personajes en el Saladero [...]». 
63. FERRERAS, Juan Ignacio: Catálogo de novelas y novelistas españoles del siglo XIX, Madrid, Cátedra, 1979, pp. 219A.

Rechaza F. la autoría ayalina, atribuida por Palau (Manual del librero hispano-americano), de Los terremotos de Andalucía o justicia de Dios, novela debida a Ángeles López de Ayala y Molero; nuestro escritor dejó incompleta la titulada Gustavo, «una novela amorosa con algún detalle escabroso».

64. GaRCía-CAmino, Víctor Gerardo: Vida y obras de Antonio Hurtado. Aportación para su estudio, Cáceres, 1977.

Contiene varias referencias a Adelardo López de Ayala en virtud de la amistad que les unió a ambos, puesta de manifiesto en su colaboración en El curioso (1853), adaptación teatral de la novela corta cervantina del curioso impertinente. Hurtado dedicó a Ayala el drama histórico Entre el deber y el derecho (1873) y Ayala, ministro de Ultramar en el primer gobierno surgido de la revolución de septiembre de 1868 , le tuvo entre sus colaboradores más inmediatos.

65. GarCÍA GutiÉRREZ, Antonio: «A Don Adelardo López de Ayala», en Los Lunes de El Imparcial, Madrid, 11-I-1880.

Es un soneto de emocionada despedida al colega y amigo recientemente fallecido.

66. GASPAR, Enrique: «Un cuento de Ayala», Majaderías, Valencia, s.a. [1889], pp. 215-222.

En forma de carta, dirigida a Emilio Arrieta, proclama G. su admiración por Ayala - «ejercía sobre mí la fascinación de lo legendario, inspirándome algo semejante al terror de los antiguos por la divinidad»- y recuerda cuándo y dónde le conoció (1863, en el camerino de Teodora Lamadrid, teatro del Circo) y alguno de sus encuentros posteriores.

67. GIES, David T.: El teatro en la España del Siglo XIX (traducción de Juan Manuel Seco), Cambridge University Press, 1996, pp. 345-359.

Ayala es tratado dentro de un extenso capítulo (el sexto: «La alta comedia, y la baja») y para G. «su teatro es algo más altisonante que el de Tamayo, algo menos convincente a escala humana, pero es, no obstante, una importante pieza de transición entre la pose emocional de las últimas obras románticas y las comedias de salón más sutiles y psicológicas de principios del siglo XX». El dinero constituye la principal motivación temática de sus obras más importantes, desde El tejado de vidrio (1857) hasta Consuelo (1878) pasando por El tanto por ciento (1861) y El nuevo Don Juan (1863), cuatro títulos comentados favorablemente atendiendo a su argumento e intención aleccionadora.

68. Goenaga, Ángel y Maguna, Juan P.: Teatro español del siglo XIX. Análisis de obras, New York, Las Américas, 1971, pp. 295-343.

En el capítulo VIII de este libro o manual escolar sus autores presentan a Ayala como destacado cultivador de la llamada alta comedia y ana- 
lizan dos de sus obras: El tanto por ciento y Consuelo, ambas, dramas de tesis, pero sin que en ningún caso «el afán de demostración tuerza ni siquiera flexione la marcha de la acción». Luego de una breve noticia biográfica de Ayala (en la que advertimos el error de darle por nacido en 1827), viene el repaso de dichas obras: argumento, estructura, personajes, técnica y estilo, crítica coetánea y posterior.

69. GONZÁleZ LóPEZ, Emilio: Historia de la Literatura Española. La Edad Moderna (siglos XVIII y XIX), New York, Las Américas, 1965, pp. 540-544.

En la no muy abundante obra ayalina destaca G.L. sus versos, distinguidos por el cuidado de la forma - «se percibe particularmente la influencia de los poetas sevillanos, que, como Rioja, representan la transición del siglo XVI al XVII»-, y sus piezas pertenecientes a la llamada alta comedia, convertido el autor en «el campeón del espíritu burgués español que triunfará, después de las varias experiencias políticas que siguieron a la Revolución de septiembre, en la restauración monárquica».

70. Guaza y Gómez Talavera, Carlos y Antonio Guerra y AlarCóN: Músicos, poetas y actores. Colección de estudios crítico-biográficos de Eslava, Ledesma, García Gutiérrez, Hartzenbusch, Ayala, Romea y Máiquez, Madrid, 1884.

Ambos autores, periodistas de profesión en diarios madrileños, ofrecen un conjunto de semblanzas más biográficas que críticas relativas a músicos, literatos y actores coetáneos con quienes tuvieron algún trato. Por lo que respecta a Ayala combinan la mera presentación del personaje - «lejos de ser un poeta romántico y melenudo, como su faz indicaba, era realista, pero realista en el buen sentido de la palabra [...] es la personificación del realismo, pero no del realismo asqueroso y descarnado que se quiere importar ahora del extranjero, sino el bello y artístico realismo que tuvo su origen en nuestros escritores del siglo de oro» (p.166) - con el ataque a la sociedad burguesa corrompida por su afán obsesivo de riqueza y triunfo en la vida - «[...] las contiendas que el interés del dinero riñe a cada instante con los sentimientos generosos y los afectos dulces del corazón» (p.167)—, asunto de las piezas de Ayala pertenecientes a la alta comedia.

71. Guerra y Alarcón, Antonio: Vid. Guaza y Gómez Talavera, Carlos.

72. GUTIÉRREZ GAMERO, Emilio: Mis primeros ochenta años (Memorias), Madrid, Aguilar, tomo II, pp. 291-294.

G.G. tiene palabras elogiosas para el literato Ayala (el poeta, sobre todo) - «leo sus versos con placer, algunos de los cuales hubiera firmado Calderón de la Barca»-, pero no así para el político pues «nunca pude comprender cómo López de Ayala, que tomó parte tan activa en la Revolución de septiembre y cuyas ideas parecíanme al unísono de aquel movimiento 
liberal, se hiciera luego reaccionario y esclavo de los conservadores. Quizás le pareciese más pintoresco y poético figurar en las filas de la gente acaudillada por Cánovas, que entre la bullanguera muchedumbre democrática $[\ldots] »$.

73. HARLAN, Mabel Margaret: «The date of 'El tejado de vidrio', with a bio-bibliographical note on D. Adelardo López de Ayala», Hispanic Review, VI, 1938, pp. 236-249.

H. aclara, en primer lugar, el año del estreno de El tejado de vidrio, situado por diversos tratadistas en años distintos: 1856, 1857 o 1861, para concluir, merced a la utilización de la prensa de la época, que se efectuó el día 30 de abril de 1856, en el madrileño teatro del Príncipe por la compañía de la que formaban parte Teodora Lamadrid y Julián Romea. H. plantea seguidamente la cuestión (también debatida entre los tratadistas) relativa al año de nacimiento de Ayalá $-1828,1829$ o 1831- y, a falta de un documento como la partida de nacimiento del escritor, concluye, apoyándose en alusiones contenidas en el epistolario publicado por Pérez Calamarte, que fue en el primero de los años mencionados. Por último, ordena cronológicamente la no muy extensa bibliografía «de» Ayala.

74. Hunter PeAK, J.: Social Drama in nineteenth century Spain, Chapel Hill, University of Norht Carolina Press, 1964.

La condición de «drama social» en el teatro moderno español comienza para H.P. con Jovellanos (El delincuente honrado), sigue con algunos autores románticos (Martínez de la Rosa o Ventura de la Vega) y se adentra en la segunda mitad del XIX, cerrando el conjunto Joaquín Dicenta; en él figura Ayala, fiel observador de la sociedad burguesa del momento, autor de Consuelo, «una buena comedia de tesis» entre cuyos rasgos más relevantes cuenta «la escasez de material no esencial» ya que su asunto «se desarrolla en línea recta, sin la más leve sugerencia que distraiga». Añádase que «la delineación de caracteres es excelente» y que la lección moral de la pieza se desprende naturalmente del desarrollo de la misma.

75. Lasso DE La Vega, Francisco de P.: Vid. Díaz DE Escovar, Narciso.

76. LÓPEZ, Julio: La poesía y el teatro realista, Cuadernos de estudio, serie Literatura número 15, Madrid, editorial Cincel, 1981, pp. 38-40.

Los varios párrafos de este repaso del teatro ayalino se dedican exclusivamente a El tanto por ciento, un ejemplo de alta comedia con sus más y sus menos ya que, junto a determinados valores literarios - la correcta versificación, el vigor del diálogo o el lenguaje-, señala L. incompleteces o deficiencias como que «el análisis [de personajes y situaciones] es poco profundo».

77. LOTT, Robert E.: «On Mannerism and Mannered Approaches to Realism in Un drama nuevo, Consuelo and Earlier Nineteenth Century Spanish Plays», Hispania, 54, 1971, pp. 844-851. 
L. entra en la disputada cuestión del realismo efectivo o no de una parte de la literatura española decimonónica y respecto de Tamayo y Baus y Ayala, autores aludidos en el título de su artículo, sostiene que sólo ofrecen enfoques manieristas del realismo o intentos más bien insuficientes de retratar la realidad elegida como motivo.

78. LUCEÑO Y BECERRA, Tomás: Memorias... a la familia, Madrid, 1905.

El comediógrafo y periodista L. fue secretario de Ayala en el sexenio revolucionario y su relato ofrece diversos recuerdos del autor de Consuelo.

79. Maguna, Juan P.: Vid GoENAGA, Ángel.

80. MARÍn, Diego: «El valor de época de Adelardo López de Ayala», Bulletin of Hispanic Studies, XIX, 1952, pp. 131-138.

La opinión mantenida por M. es que «pocas reputaciones literarias del siglo pasado habrán sufrido un eclipse comparable al de Adelardo López de Ayala», y trata de explicar el hecho reparando en que su obra dramática quedó excesivamente lastrada por diversas circunstancias de su época, componentes siempre efímeros.

81. MÉNDEZ BEJARANO, Mario: Diccionario de escritores, maestros y oradores naturales de Sevilla..., Sevilla, 1922, tomo III, pp. 384-387.

Apretada noticia bio-bibliográfica sobre Ayala, «genio reflexivo [que] acometió la depuración del gusto» de actores y espectadores estragado por ciertas exageraciones románticas. Reivindica M.B. la naturaleza sevillana de nuestro escritor pues Guadalcanal, donde nació, aunque perteneciera entonces civilmente a la provincia de Badajoz, «ni en lo jurídico, ni en lo eclesiástico, ni en lo militar, ni en lo académico dejó nunca de pertenecer a Sevilla», y le elogia como orador. Respecto de la novela Gustavo afirma que «no se comprende qué fin pudiera llevar el autor al escribirla, como no fuese el de demostrar con toda su lobreguez el triunfo del vicio sobre la virtud. Tiene todo el corte de una novela de Eugenio Sué o de Paul de Musset, pero es obra realmente notable».

82. MenÉNDEZ Pelayo, Marcelino: Vid. VAlera, Juan (1946).

83. Molins, Marqués de: Discursos leídos ante la Academia Española en la recepción pública de Don Adelardo López de Ayala..., Madrid, 1870./ /Contestación del Marqués de Molins, pp.49-84.

De estas páginas de contestación al recipiendario, cuyo discurso trató sobre el teatro de Calderón, destaco el señalamiento de dos épocas y tendencias en la obra dramática ayalina: imitador, primeramente, del teatro español del XVII en piezas como Un hombre de estado o Rioja y, tiempo después, distinguido por «fantasear los cuadros de la edad presente con viveza de expresión, animado movimiento y brillantez de colorido» (caso de El tanto por ciento o Consuelo). Destaco asimismo el muy favorable comentario a la refundición ayalina de El alcalde de Zalamea, con ciertas modificaciones — supresiones, especialmente-acertadas según $\mathbf{M}$. 
84. Nombela, Julio: Impresiones y recuerdos, Madrid, editorial Tebas, 1976, p. 165.

Da noticia, aunque sin nombrar a Ayala, uno de los protagonistas de la historia, de la desdichada relación amorosa que hubo entre el escritor y la famosa actriz Teodora Lamadrid, intérprete de alguna de sus obras dramáticas.

85. OtEYZA, Luis de: López de Ayala o el figurón político-literario, Madrid, 1932 (número 25 de la serie «Vidas españolas e hispanoamericanas del siglo XIX»).

La palabra «figurón» advierte desde el título del libro cuál es la actitud del poeta y novelista extremeño $O$. hacia su colega y paisano, decididamente desfavorable para época y personaje, a quien niega el pan y la sal como político - caracterizado «por su desaprensión, que le llevará a medrar en todos los regîmenes»- y 'como literato - cuyas obras, «caso de representarse hoy, serían un peligro pues padecería la integridad del local de espectáculos en que tan arriesgado experimento se realizara»- Aparte semejante menosprecio, nada importante añade $O$. a lo ofrecido cuarenta años antes por Solsona y Baselga (número 71).

86. PAlaCio VAldÉs, Armando: «Don Adelardo López de Ayala», Nuevo viaje al Parnaso, en Obras completas de Armando Palacio Valdés, Madrid, Aguilar, 1945, tomo II, pp. 1253-1259.

Nuevo viaje al Parnaso es un conjunto de ocho semblanzas que tienen como protagonistas a otros tantos poetas líricos y dramáticos contemporáneos del semblancista, López de Ayala entre ellos; fueron originalmente artículos de prensa recogidos después en volumen. Uno de los mayores méritos del dramaturgo Ayala consiste (según P.V.) en que muy pocos como él han acertado a retratar cumplidamente la sociedad española del momento tal como lo atestiguan El tejado de vidrio o El tanto por ciento; en Consuelo llama la atención el desenlace que, «sencillo, natural y lógico», muestra «la soledad espantosa a que su egoísmo conduce a la protagonista». Otros méritos ayalinos son la «perfecta regularidad» y la «discreción» que presiden sus obras pero al crítico, que dice preferir «lo grandioso a lo correcto», le gustaría más verle «impulsado por una fantasía viva y espontánea» en busca de «nuevos e ignotos derroteros para el arte».

87. PeCEllín LANChARRo, Manuel: Literatura en Extremadura, Badajoz, Universitas Editorial, 1981, tomo II, pp. 73-87.

Semblanza bio-bibliográfica acompañada de una antología de la obra ayalina integrada por la Epistola a Emilio Arrieta y la última escena de $E l$ tanto por ciento. P.L. sitúa a Ayala en una «generación intermedia» entre romanticismo - no es «un adepto del teatro romántico estridente, violento»- y realismo - «no es un realista convencido: elimina de su obra todos los elementos desagradables [...]»-; lo suyo fue «construir valiosos cuadros costumbristas - a menudo críticos - de la burguesía ya dominan- 
te, obsesionada por el afán de dinero» pero nuestro dramaturgo «no lleva sus análisis a las causas últimas, infraestructurales, de dicha situación».

88. PÉREZ JimÉneZ, Nicolás: Perfiles biográficos, Badajoz, 1889.

No he podido consultar este libro, una serie de semblanzas biográficas de extremeños ilustres paisanos del autor; lo cita Solsona y Baselga en la página 27 de su libro Ayala. Estudio político.

89. PICón, Jacinto Octavio: Ayala. Estudio biográfico, Madrid, La España Moderna, s.a.

P. comienza refiriéndose a la importancia de dramaturgos como Ayala y Tamayo y Baus que con sus obras satisficieron el deseo de «naturalidad y poesía» sentido por los espectadores, cansados ya de la «acción epiléptica» y el «lirismo hueco» ofrecidos por ciertos autores afectos al romanticismo. Las piezas teatrales ayalinas se distinguen, contrariamente, por el pensamiento moral que las informa -así en El tejado de vidrio, El tanto por ciento, El nuevo Don Juan y Consuelo- y también por un riguroso planteamiento y desarrollo argumental «que tiene algo de arquitectónico». Un breve repaso a la biografía de Ayala completa el folleto piconiano.

90. Revilla, Manuel de la: «Consuelo», en Críticas de D. Manuel de la Revilla, $1^{\mathrm{a}}$ serie, Burgos, 1884, pp. 45-65.

Para R. el estreno de Consuelo ha sido un felicísimo acontecimiento pues piensa que con él se «inaugura la regeneración de nuestro teatro». Poco suponen algunas deficiencias que el crítico advierte en la obra, que es «creación admirable» donde «reina la pura belleza de la forma»e impera «el buen gusto». La sencillez, la realidad de la historia ofrecida, el diestro manejo de los recursos técnicos y «un diálogo primoroso» cuentan entre las excelencias de Consuelo así como la adecuada caracterización de los personajes, entre los cuales destaca, pese a su categoría de secundarios, la pareja de criados a cuyo cargo corre el componente cómico.

91. RIVAS, Natalio: Estampas del siglo XIX. Episodios históricos..., Madrid, Editora Nacional, 1947, pp. 56-57 y 60-63.

Noticias sobre El Padre Cobos (1854-1856), periódico enemigo del gobierno progresista del general Espartero; Ayala fue redactor del mismo, junto a escritores como Selgas, Navarro Villoslada o Ceferino Suárez Bravo, y todos eran firmantes anónimos de los textos - prosas y versos, serios y festivos - radicalmente contrarios a la situación política imperante.

92. Rodríguez VARo, Vicente: Artículos en El Contemporáneo, Madrid, días 4, 15 y 16 de junio de 1871, sin firma.

R. V. juzga duramente la comedia El tanto por ciento; entre otros reparos hablaba de una «representación sórdida de la sociedad contemporánea», de una intriga que era «ilógica» y cuyos personajes se distinguían por «la falta de verosimilitud». (A tales reparos contestaría en el mismo periódico, refutándolos, José de Castro y Serrano, número 27).

93. RuANo y CoRbo, José María: Estudio analítico de la poesía dra- 
mática en el drama «Consuelo» de Ayala, con un discurso sobre el método de enseñanza..., Madrid, 1901.

El catedrático de Retórica y Poética R. y C. utiliza el drama ayalino como medio para deducir de su análisis las reglas que presiden la creación de la obra dramática, deducción que servirá para que se «graben profundamente en la inteligencia primero y en la memoria después» de los alumnos. Quedan ilustradas de este modo cuestiones como la acción, la verosimilitud, las tres partes obligadas en una pieza teatral (exposición, nudo y desenlace), los personajes, etc. La «hermosa obra» de Ayala, ejemplo de «precisión y sobriedad» y retrato de «nuestra época actual», se presta para semejante ensayo didáctico.

94. RUIZ RAMÓN, Francisco: Historia del teatro español (desde sus orígenes hasta 1900), Madrid, El Libro de Bolsillo número 66 (Alianza Editorial), 1967, pp. 449-452.

Bajo el título «Los dos dramaturgos de la 'alta comedia'» (apartado segundo del capítulo III de su libro) se ocupa R.R. de la llamada alta comedia, cuya función parece ser «desenmascarar a los enemigos de la sociedad y el inquietar en la medida de lo posible la buena conciencia de la sociedad burguesa del patio de butacas» y, asimismo, de cómo la cultivan Ayala y Tamayo y Baus cuyos «personajes y conflictos están hechos a la medida de la tesis sustentada por los autores». Muy breve resulta la atención prestada a Ayala — nada más que 23 líneas-y sumamente incompleta pues se queda en las piezas de asunto histórico y se olvida de las posteriores y más logradas.

95. SHAw, Donald L.: Historia de la Literatura Española. El siglo XIX (traducción de Elena Calsamiglia), Barcelona, editorial Ariel, 1973, pp. 133-138.

El tanto por ciento y Consuelo son las obras ayalinas que merecen mayor elogio de S. pues la primera «es una muestra notablemente ingeniosa de carpintería teatral» y la segunda resulta como teatro «espléndidamente eficaz, con su soberbia escena final en cada acto»; no demasiado lejos de ellas en cuanto a mérito quedan El tejado de vidrio, que resiste el cotejo con El hombre de mundo de Ventura de la Vega, y El nuevo Don Juan, cuyo castigo como pecador está (signo de los tiempos) no en las manos de Dios, sino en las de la comunidad social cuyas reglas quebranta.

96. Solsona y BASElga, Conrado: Ayala. Estudio político. Premiado por el Congreso de los diputados, Madrid, 1891.

El Congreso de los diputados convocó en 1890 un concurso para premiar un estudio biográfico del que fuera «su ilustre Presidente» y lo publicó a su costa en edición de dos mil ejemplares. Periodista, jurídico militar y político, S. y B. compuso una semblanza en simpatía de Ayala, casi exposición panegírica de sus méritos como escritor relevante y político destacado aportando abundante información de primera mano, si bien en 
el examen de la obra literaria ayalina resulta demasiado breve y ligero; remata los once capítulos del trabajo con la siguiente rotunda conclusión: «Ayala fue como poeta todo cuanto podía ser, y todo lo que quiso ser como político».

97. TORRES NEBRERA, Gregorio: Antonio Hurtado Valhondo y Adelardo López de Ayala. Entre literatura y política, Cuadernos Populares, número 23, Mérida, 1988.

Se trata de dos escritores extremeños «absolutamente coetáneos, nacido uno al norte de la región y otro al sur, que coinciden en varios momentos de su vida, que llegan a colaborar juntos en un proyecto literario, y que mantuvieron un parecido interés por destacar en la vida pública de aquellos años». Luego de una breve pero documentada noticia biográfica, T. N. se ocupa de la poesía ayalina, en la que destacan varios sonetos amorosos y sendas epístolas a sus amigos Arrieta y Zabálburu, "perfectamente encuadradas en la tradición renacentista hispana»; dedica especial atención a las piezas de alta comedia, todas ellas estructuradas «sobre dos elementos claves: la pareja, el matrimonio, y un factor variado (el don Juan de turno, la ambición, la presión de prestamistas usureros, etc.) que pone en peligro la estabiblidad de aquélla»; trata asimismo de la novela Gustavo, único intento de Ayala en el género y texto inacabado, en algunas de cuyas páginas se advierte una huella teatral: «las descripciones de los diversos lugares donde la acción (más diálogo que acción) transcurre son perfectamente equiparables a los típicos espacios de salones burgueses donde se desarrolla la trama de la mayoria de sus obras». Una bibliografía básica y una brevísima antología cierran el cuaderno.

98. VALBUENA PRAT, Ángel: Teatro moderno español, Zaragoza, 1944, pp. $94-102$.

Pertenecen dichas páginas al capítulo «El drama y la comedia de la época realista» y son un acertado enjuiciamiento de la dramaturgia ayalina, dividida en dos épocas o tendencias: el drama histórico, «de derivación romántica pero de intención y tono completamente diversos a la escuela de donde partían» y la alta comedia, que «corresponde al sentido realista de la segunda mitad del XIX». Señala V. aciertos en algunas de esas piezas y también -en El tanto por ciento- «cierta ñoñez de los momentos sentimentales», aunque en todas ellas resultan notorios «la destreza de la acción y el cuidado de la forma».

99. VAlera, Juan y MENÉndez Pelayo, Marcelino: Epistolario de Valera y Menéndez Pelayo 1877-1905..., Madrid, Espasa-Calpe, 1946.

En algunas de las cartas cruzadas entre V. y M.P. aluden ambos nada favorablemente a la obra literaria ayalina. Si don Marcelino (carta 169, 4XI-1885) comentaba: «se acaban de publicar juntas en un volumen las poesías líricas de Ayala. ¡Qué colección de pobrezas y tonterías!», don Juan no se quedaba atrás en el rechazo y creía (carta 202, 2-VII-1886) que 
solamente «la mezquinería, cursería y depravación del gusto en España [hacen] que haya reputaciones como de la Ayala, por ejemplo, falsas hasta para los mismos que la hacen, pues estoy seguro de que nadie lee ya a Ayala elogiándole por fe».

100. VAlERA, Juan: «Revista de Madrid. Cartas al director de la $R e$ vista Peninsular», Obras completas de Juan Valera, Madrid, Aguilar, 1949, tomo II, p. 72.

Entre los diferentes acontecimientos culturales madrileños recientes con los que V. nutre sus crónicas mensuales para la Revista Penínsular figura en esta ocasión el estreno en el teatro del Príncipe de El tejado de vidrio, cuyo asunto considera el crítico «ingenioso en extremo y propio de la comedia» aunque haya sido motivo de opiniones discordantes respecto a la lección moral que se desprende de la obra, asunto en el que no entra V. puesto que hacerlo equivaldría a elucubrar ahora sobre «si el teatro es sólo un honesto recreo o una escuela de costumbres».

101. - :Examen imparcial de la crítica contra El tanto por ciento», Obras desconocidas de Juan Valera, Madrid, Castalia, 1965, pp. 154-159.

Se trata de unas «cuartillas manuscritas» dadas a conocer por el erudito Cyrus C. DeCoster. Fueron escritas por V. para terciar en la polémica mantenida en las páginas del diario madrileño El Contemporáneo entre Vicente Rodríguez Varo (número 67) y José de Castro y Serrano (número 27) a propósito de El tanto por ciento; V. se inclina más a la opinión favorable del segundo pues considera que con sobrados motivos despertó esa obra «el entusiasmo de los literatos y del público».

102. VALlE InClán, Ramón del: La corte de los milagros, Obras completas de Ramón del Valle Inclán, Madrid, editorial Plenitud, 1952, tomo II, pp. 857 y 858-860.

En el apartado IV del libro segundo («Ecos de Asmodeo») de La corte de los milagros (1927) entra López de Ayala en la tertulia de los marqueses de Torre-Mellada - «Era el que entraba un caballero alto, fuerte, cabezudo, gran mostacho y gran piocha»-, y en el apartado VI se convierte en el centro de una conversación con varias alcurniadas señoras; más que el asunto político de tal conversación importa para el caso la breve presentación del recién llegado como «el figurón cabezudo y basto de remos, autor de comedias lloronas que celebraba por obras maestras un público sensiblero y $\sin$ caletre. [...] Tenía el alarde barroco del gallo polainero. [...] Era gongorino y rutilante en el estrado de las damas». Más adelante (apartado XXII) esos tertulianos asisten en el Teatro de la Cruz al beneficio del actor Julián Romea cuya compañía representa El alcalde de Zalamea en la refundición ayalina y V.I. recoge la opinión de «un crítico flaco, miope y pedante» para quien «nuestro Adelardo se ha parangonado, se ha parangonado con el genio de Calderón. ¡De Calderón! Ayala no ha refundido, no ha refundido; ha colaborado. Como Calderón había antes colabo- 
rado con Lope. ¡Con Lope! El tema inicial pertenece al Fénix. Ayala ha igualado la versión calderoniana en sus más felices momentos. ¡En los más felices de Calderón! ¡Igualado!».

Más intervenciones de Ayala, intervenciones al paso, encontramos en otros pasajes de La corte de los milagros y, también, en ;Viva mi dueño!. Ocurre lo mismo en Baza de espadas, cuando la actividad conspiradora de Ayala, próximo el estallido revolucionario, se intensifica; V.I. aprovecha su comparecencia para reiterar calificativos y expresiones marcadamente desfavorables como «pomposo», «gallo barroco» o «campanudo».

103. VV.AA.: Veinticuatro diarios (Madrid, 1830-1900). Artículos y noticias de escritores españoles del siglo XIX, Madrid, C.S.I.C., 1972, tomo III (letras L-P), pp.75-90.

Un total de 313 breves entradas que ofrecen noticias acerca de López de Ayala (biográficas y literarias) y, también, versos suyos tomados de publicaciones madrileñas como La Iberia, Heraldo de Madrid o La Nación.

104. YXART, José: El arte escénico en España, Barcelona, 1894, tomo I, pp. 40-46.

Pertenecen esas páginas al apartado que estudia la situación del teatro español entre 1850 y 1868 aproximadamente, período presidido por Ayala y Tamayo y Baus, a quienes anima «el deseo de fundir la mayor belleza ética con la mayor belleza dramática», autores uno y otro de la clase de «los perfectos, equilibrados y templados» frente a «los geniales y desarreglados» del tiempo anterior. Ayala acierta a sortear los peligros del arte docente, observa la sociedad en torno y reviste tal contenido con «una forma rimada, irreprochable, sobria, nielada»; Consuelo, «una obra magistral», es la culminación de la dramaturgia ayalina comenzada por algunas piezas de asunto histórico a las que Y. llama «dramas de costumbres retrospectivas». 